\title{
The Use of Dictionary for Theological Purposes
}

\author{
Sade Olagunju PhD \\ English Unit, Department of General Studies \\ Ladoke Akintola University of Technology \\ P.M.B. 4000, Ogbomoso, Nigeria \\ boladeolagunju@gmail.com
}

\section{INTRODUCTION}

The use of English for theological purposes falls within the area of English Studies identified as English for Special Purposes (ESP). The variety of English needed for theological enterprise is special because of the nature of theology itself. Hence, the use of the dictionary for theological purpose deserves scholarly attentions. Theological students need to write term papers, teach bible studies, preach messages, write tracts, make public awareness through posters and handbills, amongst other activities. These pastoral activities require good mastery of language as it relates to correct spelling of words, word form and word formation processes, grammatical and stylistic information about words, lexical components of word, sense relations, as well as the origin of words which are all provided for in the dictionary. Thus, the good knowledge of the dictionary and its usages will ensure effective communication in theological texts and equally avert the problem of accessing theological texts.

\section{DEFINITION AND CHARACTERISTICS}

The dictionary can be defined as a reference resource in printed or electronic form that consists of an alphabetical list of words with their meanings and part of speech, and often a guide to accepted pronunciation and syllabifications, irregular inflections of words, derived words of different parts of speech, and etymologies. A dictionary maybe monolingual or bilingual, abridge or unabridged. The abridged dictionary is a reduced version one that is usually comprehensive and voluminous since it contains the most detailed information about a word. The English dictionary which contains only English words is an example of a monolingual dictionary where a dictionary which contains words from the languages like Germans-English Dictionary is an example of a bilingual dictionary.

One salient characteristic of the dictionary is its correctness. This indicates that the dictionary enjoys the attribute of 'lexicographical infallibility'. That is, the dictionary is accurate in spellings, punctuation and other forms of grammatical and stylistic information.

The lexicographical infallibility of the dictionary notwithstanding, there are lots of changes being effected in the dictionary in recent times. Factors like geographical variation, national idiosyncrasies, and social variations are responsible for some of the changes. As the world, we can begin to expatiate on these factors that account for language change because of dictionary accounts for most vocabulary for most vocabulary of language. The global use of English language across many nations of the world has resulted in many varieties or styles which are referred to as "Englishes". The need to account for the vocabulary of the geographical variations and national idiosyncrasies of these unavoidable. Equally, colloquial word, slang words, words with pompous overtones, words with pejorative overtone are coming into use and this reflect the social factors binging about changes in the dictionary.

Moreover, new words are emerging or coming into language use on daily basis. The advancements in science, technology and all fields of human endeavour are basis to the emerging new words. As human's quest for knowledge is increasing, new words are developed/coined to name new ideas and the actualization of the ideas. Example of such relatively new invention is Global System for Mobile Communications (GSM). GSM came with its language and the new and modern dictionary must definitely record some of its register or vocabulary, such as handset, mobile phone, headset, earpiece, 
phone case, call log, chat, ping, flash message, text message, SMS, MMS, Voicemail, browser, ringing tone, wallpaper, home screen, gallery, call divert, amongst others.

Another characteristic of the dictionary is that it has its limitation on the number of word entry because no dictionary could be complete record of all the words in any language.

\section{TYPES OF DICTIONARIES}

There are two types of dictionaries namely: General and Specialize.

\subsection{General Dictionaries}

These are dictionaries that contain information that any speaker or user of English would require about the words of the language. They give almost all the needed pieces of information on the entry words. The information range from correct spelling, meaning relation, correct usage lexical relation (like oppositeness or nearest in meaning), and origin of the words. Examples of such dictionaries are: The random House College Dictionary, The Oxford Advanced Learners' Dictionary, The Chamber Dictionary, Collins Cobuild English Dictionary, Cambridge International Dictionary of English, Longman Dictionary of Contemporary English etc.

\subsection{Spe cialized Dictionaries}

Specialized dictionaries include Thesaurus, The Dictionary of Idioms, Dictionary of Spellings, English Pronouncing Dictionary, amongst others which act as supplements to the general dictionaries. Specialize dictionaries also cover the dictionaries that deal with specific fields of study or disciplines. Examples of the dictionaries in this category are The Dictionary of Stylistics, Medical Dictionary of Anatomy, Dictionary of Art Terms, Dictionary of Chemistry, Dictionary of Theology, The New International Dictionary of the Christian Church, and dictionary of False Terms amongst others.

\section{USE OF DICTIONARIES}

Dictionaries have various uses. And this section will be devoted to some of these functions, these are discussed below:

\subsection{Spelling}

One of the main functions of the dictionary is to provide the correct spelling of any entry word. Words that have similar spellings may have more than one meaning and a word may also have more than one correct spelling and the dictionary will provide for all these. Examples of such words are; gray and grey, ax and axe.

\subsection{Pronunciation}

A theological student can learn correct pronunciation of each entry word from the dictionary. For example word such as naïve /naii:v/, secret /si:krət/, liturgy /litərd i/, faith /feı日/, ecumenical /i:kju:menikl/, isle /ai/ etc. the pronunciation of a word is place immediately after its entry in the dictionary.

\subsection{Stylis tic Information}

The dictionary also provides stylistic information of the entry words. We do come across some labels in the dictionary which indicate different social attitudes towards words (Quirk et al, 1973:7). Example of such labels are derog, euph, apprec, humor, fml, informl, archaic etc.

The label 'derog' means derogatory, 'euph' means euphemism, 'apprec' is the direct opposite of derogatory words and means appreciative. Humour, which is written as joc, means jocular, fml and infml means formal and informal words respectively. Archaic shows that the entry words are obsolete and outdated. Examples of words with this tag are 'brethren', 'damsel'. 'Beget' etc.

\subsection{Etymology}

This refers to the origin of a word. Some dictionaries, most especially the unabridged ones make reference to the etymology of words. For example, naïve has French origin. A word may be associated with some specific region or country and the dictionary will label such words based on the markers such as follows: 


\begin{tabular}{ll}
\hline AmE - & American Englsih \\
BrE - & British Englsih \\
SAfrE - & South African English \\
WAfrE - & West African English \\
IrE - & Irish English \\
Scot.E - & Scottish English \\
Can.E - & Canadian Englsih
\end{tabular}

The following are some of the examples

\begin{tabular}{|l|l|l|}
\hline BrE & AME & FrE \\
\hline Car & Faucet & Conceal \\
\hline Winder & Duplex & Nourish \\
\hline Medicine & Windshield & Naïve \\
\hline Number plate & Drug store & Aroma \\
\hline Pharmacy & Trunk & \\
\hline Nappy & Diaper & \\
\hline
\end{tabular}

\section{GRAMMATICAL AND SEMANTIC INFORMATION}

The dictionary provides different grammatical information about the entry word. This include: parts, compounding, capitalisation, meaning and usage.

\subsection{Parts of Speech}

The dictionary usually specifies the part of speech of the entry word for example if the word is a noun, some dictionaries will go further to categorize whether it is countable or uncountable noun. For example, the word "sand" is entered thus: sand /sand/ noun [U] meaning that "sand" is an uncountable noun.

Furthermore, words such as advice, apology, breath, example, glory, knee etc, which belong to the category of noun have their verb categories such as 'advise', 'apologise', 'breathe', 'exemplify', 'glorify', 'kneel', etc and the dictionary will specify this using " $v$ ".

Some examples of other parts of speech like adjective (adj) 'abusive', 'acceptable', beautifyl etc., Adverb (adv) 'quickly', 'slowly', 'always', 'little' etc. will also be marked.

\subsection{Compounding}

Dictionaries record compound words. A compound word is simply a combination of two or more words that has meaning as one word. This may be done with or without hyphenation. Examples of such words include: Blackboard, pot-belly, loudmouth, tear gas, sawdust, duty-free, easy-going, record-player, earthquake, bee-sting, manmade, sleep-walk, baby-sit etc.

\subsection{Capitalisation}

The dictionary records appropriate use of capital. For instance, the names of persons (Folasade, Adeniyi, Caroline, Olalekan, Cyprian, Oluwaseun, adenike, etc.); the names of places (Ogbomoso, Ilorin, Gambari, Ikirun, Ibadan, Aagba, Iresa-Apa, Iluju, Osogbo, Oyo etc.); the names of countries (Nigeria, Ghana, England, South Africa, Zambia, Botswana, Mali etc.); the names of continents (Africa, Asia, Europe, Australia) the names of planets (Earth, Mars, Neptune, Uranus, Jupiter etc..), the names of months (January, February, July, December etc.) and abbreviations amongst others are all indicated with initial capital letters.

\subsection{Meaning}

The dictionary explains the meaning of the entry words sometimes in relation to other words. The relationship that is obtained among words is called lexical relations. The relationship may be in terms of the similarities, or the differences that words have. The following subdivisions further expatiate on the lexical relationship among words; synonyms, antonyms and homographs. 


\subsection{Synonyms}

Some dictionaries list synonyms (i.e. words that have similar meaning although there is no absolute or exact synonyms) of the entry words. They are usually listed near the end of an entry word with the abbreviation label "syn". Examples of such words are reliable/dependable, solemn/serious, sacred/sacrosanct, testy/irritable, endure/bear, incoherent/intelligible, religious/devout etc.

\subsection{Antonyms}

These are words which have opposite meaning of the entry works. They are indicated in some dictionary as "opp" or "ant". The following are some examples, incoming/outgoing, solemn/cheerful, coherent/incoherent, white/black, legal/illegal, etc.

Unlike synonyms, antonyms can be true or exact opposite. From the examples cited in this section, one can clearly see that antonyms have the attribute of exactness.

\subsection{Homographs}

This refers to words spelled alike but with different meanings or pronunciation or that belongs to different classes. Examples of homographs include:
a. Bank
of a river
Bank
financial institution
b. Pupil - at school
Pupil - in the eye
c. Bark - cry made by dog
Bark - outer covering of a tree

\subsection{Usage}

The dictionary teaches the usage of entry words after a clear description of the meaning. This is achieved by giving examples of how the entry word can be used in forming sentence(s). With such sentences, the language learner becomes aware of the contexts in which the word can occur and the use to which it can be put.

\section{Relevance of the Dictionary to Pastoral/Theological Experience}

Pastoral practice, being a core aspect of public speaking, demands vast vocabulary base and knowledge. As a matter of fact, pastoral practices are conceived and managed using words. The pastoral practice is a business of words/vocabulary. A pastor's day-to-day activities include counselling, preaching, and writing/reading/expounding the bible and other theological texts. This thus explains why the understanding of dictionary usage is very germane to pastoral practice. At least, in the environment where English is the second language (L2) like Nigeria, it is highly essential for pastors to have the knowledge of lexis and structures in English for communicative purposes. The dictionary as the direct reference material is very useful in exercising priestly or ministerial office. It is not all the words in the bible and theological texts that the pastor/Christian workers may understand at once. The dictionary, both general and specialized ones like theological dictionary needs to be consulted for better understanding.

Theological students learn how to prepare sermons to be delivered on the pulpit. So, for appropriate liturgical delivery, it is highly essential to be acquainted with the vocabulary one will use and to have an extensive vocabulary base. This is because pastors, as public speakers, must have adequate knowledge of the vocabulary of English to be able to impress and persuade their congregation and to be able to address their congregations based on the demographic peculiarities of the congregation such as age, gender, nationality, academic background, and social status. Getting acquainted with dictionary will not only help with word spellings, but also with the section or choice of words as well as the correct pronunciation of words.

The pastor who is well aware of the use of the dictionary is a successful one who wins the hearts of his/her congregation. This is because the pastor has adequate knowledge of the choice of diction or what we call appropriate stylistic choice. The pastor which has a good message and proper and adequate weapon of delivery catches the fancy of the congregation any day. The dictionary, being a 
resource material for pedagogical, theological, and domestic purposes among others, becomes indispensable for the user of language.

\section{SUMMARY AND CONCLUSION}

This study has been able to explain the characteristics of the dictionary as well as its importance to any user of language. We have discussed the fact that the dictionary helps for spelling correctness, pronunciation, meaning and lexical relationship, and appropriate usages. Equally, the dictionary provides users with stylistic information that will indicate whether a word is appropriate for formal usages or not and whether a word is derogatory or complimentary, amongst other stylistic implications of words.

The functions of the dictionary indicate why it is pertinent for every user of language to be conversant with and be in constant possession of the dictionary. As a matter of fact, a second language learner or a user of English will need to have at least two or more types of dictionaries. A single one may not be adequate for appropriate master of the lexicography of the English Language. Because of the comprehensiveness of unabridged dictionaries, it is encouraged that tertiary students and intending public speakers especially in the Nigerian setting where English is the official language and medium of instruction in school should one.

\section{REFERENCES}

Collins English Dictionary, 2009. Harper Collins Publisher 10th Edition.

Crystal, D.(1970)Thinking about Dictionaries. BBC English

Quirk,R. and Greenbaum, S.(1973) A University Grammar of English. Essex: English Language Book Society and Longman Group Ltd.

\section{AUTHOR'S BIOGRAPHY}

Sade Olagunju, PhD, teaches English in the Department of General Studies, Ladoke Akintola University of Technology, Ogbomoso, Nigeria. She holds the B.A, M.A, M.Phil and Ph.D. (English Language) degrees of Obafemi Awolowo University, Ile-Ife, Nigeria. 